\title{
Correction to: Progress in rheology and hydrodynamics allowed by NMR or MRI techniques
}

\section{P. Coussot ${ }^{1}$ D}

Published online: 18 November 2020

๑) Springer-Verlag GmbH Germany, part of Springer Nature 2020

\section{Correction to: Experiments in Fluids (2020) 61:207 https://doi.org/10.1007/s00348-020-03037-y}

In the original article the expression for Eq. (1) is partly missing. The correct Eq. (1) should read:

$M(t)=M(0) \exp \left(i \omega_{0} t\right)$

It must also be mentioned that this expression is in complex coordinates and concerns the spin component in the plane perpendicular to $\mathbf{B}_{0}$, while the component along $\mathbf{B}_{0}$ remains constant.

The original article can be found online at https://doi.org/10.1007/ s00348-020-03037-y.

P. Coussot

Philippe.coussot@univ.eiffel.fr

1 Laboratoire Navier, Univ Gustave Eiffel, ENPC, CNRS,

16-20 Bd Newton, 77420 Champs sur Marne, France 